Ihre Fragen zur Abrechnung und zur wirtschaftlichen Praxisführung beantwortet unser Experte Helmut Walbert, Würzburg.

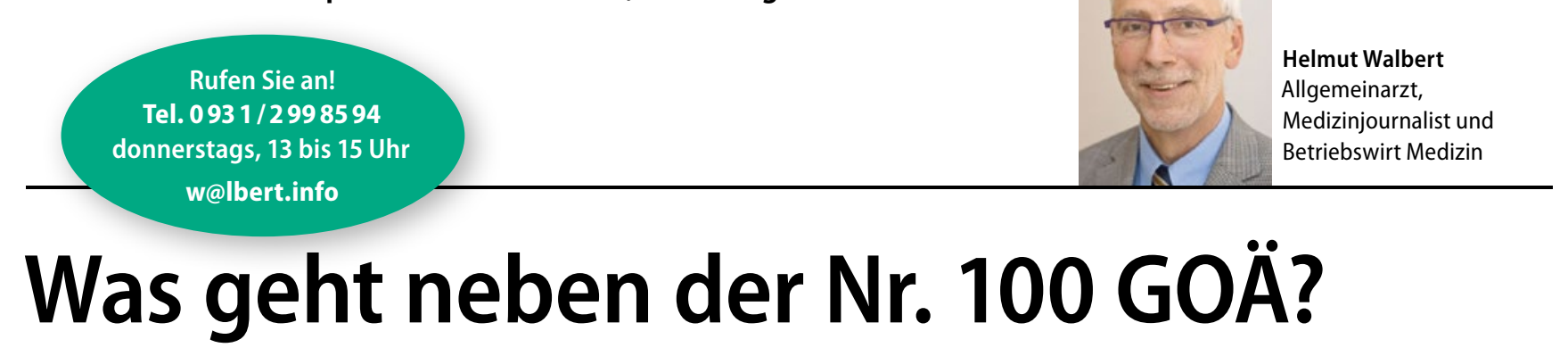

? Dr. W. Sigler, Allgemeinarzt/Notarzt, Baden-Württemberg: Kann bei einem Toten im Straßenverkehr neben der Nr. 100 GOÄ die Nr. 4 für die Klärung bestimmter Verletzungsmuster und auch die Nr. 56 als Verweilgebühr zwischen der Ausstellung der vorläufigen Totenbescheinigung und der ärztlichen Leichenschau abgerechnet werden? Dürfen in diesem besonderen Fall alle Positionen 3,5-fach gesteigert werden? Welche Kosten können des Weiteren in Rechnung gestellt werden?

!

MMW-Experte Walbert: Wenn der Einsatz über die Rettungsleitstelle erfolgte und das Meldebild ein Verletzter und nicht ein Toter war, ist der Besuch zulasten der bestehenden Krankenversicherung abzurechnen. Falls das Unfallopfer ein Privatversicherter ist, kommen die bis zur Feststellung des Todes erbrachten Leistungen hinzu.

Im Zusammenhang mit der Leichenschau fällt leider nur die Nr. 100 GOÄ an. Auf die vorläufige Todesbescheinigung kann bei tödlicher Unfallverletzung aus juristischen wie auch aus wirtschaftlichen Gründen verzichtet werden.

Gegen den Ansatz der Verweilziffer 56 spricht, dass sie laut Text „wegen Erkran- kung erforderlich" sein muss. Alternativ könnte man eine Analogziffer bilden, doch das wäre nicht wirtschaftlich, da diese höchstens 2,5-fach gesteigert werden dürfte.

Auch die Erhebung der Fremdanamnese nach Nr. 4 muss laut Text „im Zusammenhang mit der Behandlung eines Kranken“ stehen, was nicht recht zur Ermittlung von Unfallumständen passt. Neben der Nr. 100 ist sie nicht abrechenbar, da der Leistungsinhalt - auch, wenn bei analoger Textveränderung die Position inhaltlich angeglichen wird zur Leichenschau nicht notwendig ist.

Verrechenbar sind selbstverständlich die Auslagen für den Leichenschauschein als Erstattung von Auslagen nach $\$ 10$ GOÄ inklusive Umsatzsteuer. Kilometergeld kann berechnet werden, wenn man zu einem bereits Toten gerufen wird und somit nicht zulasten einer Krankenkasse abrechnen kann.

Der 3,5-fache Steigerungssatz ist mit entsprechenden Begründungen bei der Nr. immer sinnvoll, da selbst ein Betrag von 51 Euro den Aufwand keineswegs leistungsgerecht vergütet.

\title{
Ulkusbehandlung über zwei Quartale?
}

$?$ Dr. G. L., Allgemeinarzt, Bayern: Die Ulkusbehandlung erfordert mindestens drei persönliche Arzt-Patienten-Kontakte. Wenn ich bis zum Quartalsende nur zwei Kontakte habe, dann aber im nächsten Quartal sofort ein dritter Kontakt erfolgt, kann ich die Nr. 02310 EBM dann im neuen Quartal abrechnen?

!

MMW-Experte Walbert: Leider nein!

$\mathrm{Zu}$ den obligaten Leistungsinhalten gehören laut Legende mindestens drei persönliche Arzt-Patienten-Kontakte „im Behandlungsfall“. Der Behandlungsfall ist definiert als die Behandlung desselben Versicherten durch dieselbe Praxis in einem Quartal zulasten derselben Krankenkasse. Aus dieser Definition ergibt sich, dass die geforderten Kontakte im selben Quartal liegen müssen. 